\title{
Intervention to mental illness stigmatization in the community
}

\author{
Ahmet TOPUZOGLU (D) \\ Department of Public Health, School of Medicine, Marmara University, Maltepe, Istanbul, Turkey.
} Corresponding Author: Ahmet TOPUZOGLU

E-mail: ahmet.topuzoglu@marmara.edu.tr

\begin{abstract}
Stigmatization of mental illness can cause reduced access to health care services. The majority of people with mental illness do not seek help, therefore the stigma of mental illness is considered a barrier to seeking appropriate treatment. Different interventions are presented with the aim of correcting negative attitudes and beliefs concerning stigma. These interventions have different outcomes, some of them have temporarily made new awareness possible, however, in most cases positive attitudes against mental illness stigmatization or discrimination rarely develop. In this narrative review, anti-stigmatization interventions and program methods will be mentioned according to some local experiences.

Keywords: Stigma, Interventions, Social contact, Community based strategies
\end{abstract}

\section{INTRODUCTION}

There are too many consequences of stigmatization concerning the course and prognosis of mental illness. Stigmatization leads to problems in every aspect of the lives of people with mental illness problems, such as personal relationship problems, education, career, work environment, and unemployment issues. Also, stigmatization of mental illnesses can cause reduced access to health care services [1-3].

Because of the harmful consequences of stigmatization, controlling its effects is crucial and requires preventive mental health approaches. Interventions have different outcomes, some of them are temporarily successful in raising new awareness, however, attitudes against mental illness stigmatization or discrimination rarely change. Different interventions have methodological variances such as intervention intensity, the aim of interventions (knowledge, attitudes, behaviors). Recent reviews showing stigmatization interventions were found to have minor to modest effects [4-6].

Social contact with mental illness sufferers is a more effective intervention in coping with stigmatization and discrimination [6]. Education and social contact, positively change stigmatization frequencies in the community, reducing attitudes and proposed behavior related to stigmatization and discrimination. Real communication contacts are better when compared to filmed contact and didactical theoretic informative education [5].

We could not assume that all interventions are useful against stigmatization. For example, biologic or genetic explanations of mental illness causality can increase stigmatization. Length of intervention and follow up period are also important aspects for understanding the improvements on knowledge and attitudes in the community. Many research projects have short term follow-up periods [5]. In community intervention studies that evaluate knowledge and attitudes, behavioral change is rarely monitored. Public stigma reduction campaigns with mass media usage are moderately effective in the community. Attitude changes and knowledge improvements have low and modest effects on reducing the stigma [7-9].

Depression specific interventions like "Beyond Blue" and "Like Minds Like Mine" in Australia which had serial informative meetings in local area settings developed appropriate knowledge and attitudes. But, when the population group size was increased, effects of the interventions decreased to a moderate or lower level $[10,11]$.

This narrative review will discuss different intervention approaches and their capabilities worldwide. Three different types of stigma can be targets for intervention: public stigma, self-stigma, and structural discrimination. Public stigma refers 
to members of the general public countersigning negative stereotypes and discriminating against people with mental illness; self-stigma happens if people with mental illness adopt negative stereotypes for themselves, leading to reduced selfesteem, self - efficacy, and demoralization; and structural discrimination indicates rules and regulations in society that intentionally or unintentionally detrimentally stigmatized individuals [12].

\section{Intervention programs to stigmatization in the community setting}

Interventions that reduce stigmatization can be developed for a different type of stigma. The general population, patients, health workers, teachers, students, and other specific groups can be established as target groups. Perhaps one of the most effective intervention methods has been the "Open the Doors Program", a global program with different levels and different activities directed by the World Psychiatric Association. 18 countries joined this program. Mainly, the program tries to decrease stigmatization against schizophrenia patients. The "Open the Doors Program" demonstrated that defining the problem and describing solutions centrally, but giving locals the chance to express their needs and solving these needs locally was very important. Also, anti-stigma intervention models can be implemented in any country, including those which only have minimal resources to spend. Small group interventions, community involvement with community volunteers may be more efficient in anti-stigma programs [13]. There are national anti-stigma programs in the United Kingdom, Australia, Canada and New Zealand (Table I).

Table I. Examples of intervention programs

\begin{tabular}{|c|c|c|c|c|}
\hline $\begin{array}{l}\text { Intervention } \\
\text { program }\end{array}$ & Country & $\begin{array}{l}\text { Project Aim, Study Population } \\
\text { and Plan }\end{array}$ & $\begin{array}{l}\text { Intervention } \\
\text { Description }\end{array}$ & Outcomes \\
\hline See Me [14] & Scotland & $\begin{array}{l}\text { Reducing self stigma and } \\
\text { stigmatization in the community. } \\
\text { Recovery is possible from mental } \\
\text { illnesses. Should be understood } \\
\text { more widely in the population. }\end{array}$ & $\begin{array}{l}\text { Mass media campaigns, reaching } \\
\text { community with activities like arts and } \\
\text { festivals, outreach programs, local grants. } \\
\text { Change networks, workplace strategy, } \\
\text { health and social care strategy, built } \\
\text { up networks and use networks for } \\
\text { intervention. }\end{array}$ & $\begin{array}{l}\text { Elimination of stigmatization and } \\
\text { discrimination attitudes in the community and } \\
\text { demanding their rights from the community. } \\
\text { Negative stereotyping reduced in the } \\
\text { communities. } \\
\text { National and local policy more focused to } \\
\text { problems. } \\
\text { Understanding stigmatization and } \\
\text { discrimination problems widely. }\end{array}$ \\
\hline $\begin{array}{l}\text { The Opening } \\
\text { Minds Anti-Stigma } \\
\text { Initiatives [13] } \\
\end{array}$ & $\begin{array}{l}\text { Canada, since } \\
2007\end{array}$ & $\begin{array}{l}\text { Youth and Healthcare Providers, } \\
\text { News media and workforce }\end{array}$ & $\begin{array}{l}\text { Contact based strategies for health } \\
\text { personel, social contacts, workshops, what } \\
\text { to say, what to do skills. }\end{array}$ & $\begin{array}{l}\text { Trying to define effective programs in the } \\
\text { project and the critical components. }\end{array}$ \\
\hline $\begin{array}{l}\text { Like Minds, Like } \\
\text { Mine [11] }\end{array}$ & $\begin{array}{l}\text { New Zealand, } \\
\text { since } 1996\end{array}$ & $\begin{array}{l}\text { Sector development and project } \\
\text { implementation (attitudes } \\
\text { change in health services } \\
\text { area), increasing mental health } \\
\text { awareness, } \\
\text { contact people with experienced } \\
\text { mental health difficulties are } \\
\text { main components. Human rights } \\
\text { and disability rights structure } \\
\text { has a priority in the intervention } \\
\text { concept. The motto "nothing } \\
\text { about us, without us". }\end{array}$ & $\begin{array}{l}\text { Social marketing at national level, } \\
\text { community education and training with } \\
\text { different strategies. } \\
\text { Advocation. } \\
\text { Changing public attitudes;Advertising } \\
\text { campaigns working with media, art events, } \\
\text { community radio shows. } \\
\text { Changing behaviours by workshops for } \\
\text { education and trainings. } \\
\text { Changing institutional policy. }\end{array}$ & $\begin{array}{l}\text { Attitudes change. } \\
\text { Increased acceptance in the community. }\end{array}$ \\
\hline $\begin{array}{l}\text { Beyond Blue and } \\
\text { SANE }[16,20]\end{array}$ & $\begin{array}{l}\text { Australia, } \\
\text { since } 2000\end{array}$ & $\begin{array}{l}\text { Community response to } \\
\text { depression. Increasing } \\
\text { understanding of depression and } \\
\text { anxiety (in suicide condition } \\
\text { especially). } \\
\text { Reducing the influence of mental } \\
\text { illnesses and related disability } \\
\text { with these conditions. } \\
\text { Reduction stigmatization among } \\
\text { men (Because their help seeking } \\
\text { is low). }\end{array}$ & $\begin{array}{l}\text { Talking about mental health, increasing } \\
\text { mental health skilled conversation in the } \\
\text { community and family environment, } \\
\text { increasing insurance benefits for mental } \\
\text { health sufferers. Risk group interventions. } \\
\text { Digital environment interventions. }\end{array}$ & $\begin{array}{l}\text { SANE advices; } \\
\text { Direct personal contact, } \\
\text { Information alone those not change attitude, } \\
\text { Problems are not just biomedical, } \\
\text { National campaign local intervention activities } \\
\text { important, } \\
\text { National strategic plan essential, } \\
\text { Influential groups and media important, } \\
\text { Evidence production and utilization in the } \\
\text { programs essential. }\end{array}$ \\
\hline
\end{tabular}


An anti-stigma program in Scotland is a good example for clear structural goals. The "See Me" campaign increases social mobilization and creates a movement against mental health stigma. The program aims to include community participation in order to change negative behaviors towards those with mental health difficulties and to develop respect for sufferers' human rights. Individual efforts for anti-stigma are not effective, therefore, national programs must be implemented to help in developing institutional anti-stigma policies [14] (Table I).

The anti-stigma program aims to influence the general population through mass media and social contact development with an involved population in Scotland. Businesses and offices, workplaces, young people and children, parent groups, schools, health and social care settings are implementation areas. There are different methods for each of these groups, but they diverge in that the main approach should be built upon equality and human rights perspectives. An effective behavioral change is aimed at in all program courses [14].

New Zealand's “Like Minds" program on prevention of stigma and discrimination, has now been ongoing for about 20 years. The program is built upon health promotion and the approach of public health authorities, with a human rights perspective, based on experiences in the community. "Like Minds" has been a program of social evolution against stigmatization and discrimination of mental health services users, and understanding of mental health services users' problems, attitudes, and behaviors in the community. This type of national program develops over time and requires continuous developing activities with commitment. The social dimension of intervention always needs time and effort. The "Like Minds" results have shown that community awareness related to mental health issues and the efforts of suffered people to cope with their illness increases understanding in the community. Social change interventions require continuous effort and these are dynamical systems that should always be applied in the community and institutions and should also be part of the national health policy [15].

A report from the Australian SANE 2013, "A life without stigma", identifies the principles for best practice in stigma reduction as; direct personal contact with people who experience mental illness [ ]. Information alone does not change attitudes. The goals of education should include challenges real people face, how to cope with difficulties, and how they can be supportive and create messages of equality, hope, and recovery. Using social communication and creative arts and multimedia increases impact. Mental health problems are best accepted as part of our shared humanity. Mental health problems are an understandable response to a unique set of circumstances and not purely as biomedical, genetically based illnesses or a diseased state of the brain. Nations should make continuous efforts with a simple and enduring national vision. An approach that promotes human rights, community involvement, equal rights and shared responsibility is important for anti-stigma program management. One of the most effective methods for anti-stigma intervention is using multimedia and social marketing tools for developing communities. This would be a most effective method for intervention, supporting local programming and using multimedia and social marketing tools to create clear program outcomes and benchmarks important for program management. A national campaign that increases contact and education and builds consumer leadership is important, but change happens at the local level. Program evaluation for the success of the intervention is also an important component at the national and local levels. Nations should develop and present a national strategic plan that works jointly with the government and stakeholders. Multilevel plan, legislative, policy and implementation level aimed at transforming systemic change in a service system.

Specific outcomes should be monitored periodically. Also, financial support of the program plan should be long term. Community leaders and public participation are important and should support the program. Also, media relationships are very important for the dissemination of program information to the community. Evidence-based intervention and collecting new pieces of evidence in the program are important. Sharing outcomes and evidence with stakeholders and the community will feed with the information to community networks [16].

\section{Strategies for intervention programs}

When we look at anti-stigmatization programs they have strategies and tools for public stigma reduction intervention. These are awareness-raising, advocacy, protest, literacy programs, social contact [17] (Table II).

Social contact is a better and evident way of decreasing stigmatization, by developing synergy of stereotypes, expression of wrong perceptions, prejudice, and discrimination. This approach is an effective way of decreasing stigmatization. Strengthening interpersonal interactions with mental illness sufferers changing opinions and attitudes, studying the behavior of people experiencing this type of contact is important. Behavioral changing is more possible with contactbased education activities when compared to a classic didactic informative education $[17,18]$. 
Table II. Stigma reduction strategies

\begin{tabular}{|l|l|l|}
\hline Public stigma reduction & Protest & $\begin{array}{l}\text { Collectively or individually using protest against stigmatized information and } \\
\text { attitudes in public proclamations, for example, in mass media or advertorials } \\
\text { and commercials }\end{array}$ \\
\hline & Social contact & $\begin{array}{l}\text { Small-groups contact between people with mental illness in recovery and target } \\
\text { group members (e.g., local workers, employers, local citizens, teachers etc); } \\
\text { can be combined with education (e.g real personal contact with sufferers and } \\
\text { getting information from them) }\end{array}$ \\
\hline & Advocacy & $\begin{array}{l}\text { Decreasing treatment gap as a mental health policy target } \\
\text { Wobally organizing special days for mental health campaign organizations (e.g. } \\
\text { World Mental Health Day) }\end{array}$ \\
\hline Self Stigma reduction & Literacy programs & $\begin{array}{l}\text { Increasing collective information about mental health problems in the } \\
\text { community (e.g. "Beyond blue" program in Australia) }\end{array}$ \\
\hline Structural discrimination reduction & $\begin{array}{l}\text { Psychoeducation, mindfulness, cognitive } \\
\text { restructuring, empowerment, peer } \\
\text { support, disclosure, normalizing }\end{array}$ & $\begin{array}{l}\text { Narrative Enhancement and Cognitive Therapy (NECT), Self-Stigma } \\
\text { Reduction Program, } \\
\text { Consumer-Operated Service Programs (COSPs), Coming Out Proud/Honest, } \\
\text { Open, Proud (COP/HOP) }\end{array}$ \\
\hline $\begin{array}{l}\text { health programs, increased education for } \\
\text { cultural variability }\end{array}$ & $\begin{array}{l}\text { Change the cultural aspects of discrimination with education and legislation } \\
\text { especially programs for companies, schools, governmental organizations (e.g. } \\
\text { developing healthcare services utilization and stigma integration of future } \\
\text { healthcare professionals training curricula) }\end{array}$ \\
\hline
\end{tabular}

Awareness-raising interventions including daily and weekly organizing for a year should be programmed in order to increase public attention and awareness related to mental illnesses. So many stakeholders can be involved in this type of program. The best example for a public awareness-raising program is the World Health Organization (WHO) Mental Health Day October 10, every aspect of the mental health initiatives discuss mental health issues and try to attract attention nationally and internationally with awareness-raising activities, including advocation. Some countries design one-week activities which mainly aim to start discussions on mental health issues and try to increase social understanding and tolerance [17].

Literacy programs aim to develop knowledge related to mental illness, their signs and symptoms, their treatments and where to apply for attending the mental health service areas in the health system. Australian "Beyond Blue" programs aim to reduce the impact of common mental illnesses like depression and anxiety, reducing stigma and discrimination, developing helpseeking and usage of mental health services, reducing impact, disability, and mortality and increasing learning and research capacity with collaboration. This intervention program targets decreasing treatment gap-related with mental health but also indirectly targets reducing stigmatization. Literacy programs increase collective information related to mental illnesses in the community and helps individuals to find and contact the appropriate health system. Population-based information campaigns reach people, but this kind of information availability is not enough for population inclusiveness. The effect of literacy campaigns is moderate but important for mental health prevention $[17,19]$.

The "StigmaWatch" program operated since 1999 by SANE Australia is a good example (http://www.sane. org) of a protest focused volunteer network activity. People suffering from mental illness, their friends, groups, and relatives and supporters look for stigmatizing images accessible in the media and report these to SANE. This feedback from media organizations served to improve the media approach to mental illness [20].

Stigma reduction strategies categorized as public stigma reduction which are explained above may be grouped as selfstigma reduction and structural discrimination reduction (Table II). Generally, self-stigma reduction strategies contain group workings with psychoeducational techniques which include mostly cognitive-behavioral contents [21, 22]. Self-stigma reduction aims to personally change self-understanding and resolving the stigmatization component and develop insight capacity for prevention from stigmatization self-destructive effects. The instruments of intervention can be psychoeducation, cognitive restructuring, disclosure, peer support, empowerment, normalizing, and mindfulness techniques. Structural discrimination reduction related to legislation, financing mental health prevention activities and increased education for cultural variability and acceptance of variability.

Treatment gaps and health budget shortages for mental health services always create the need for mental health administration and essential services. Especially, public health authorities and other policy stakeholders need to focus on persuading government, ministry of health and institutions, local authorities even communities that understand mental health issues are essential and cannot be postponed and require more resources. Spending money for mental health is cost-effective and a good investment for health because it profits the community, keeping moral values and increasing the quality of life. WHO must continuously place mental health on the agenda [17, 23].

Stigma reduction activities in the community have different efficacy in the short term and in the long term. The most widely used intervention types tested in intervention studies 
were increasing information and contact between people with and without mental illness. Social contact is the most effective intervention for adults when there is an equal status between groups of participants, common goals for the interaction, and inter-group cooperation $[24,25]$. Disconfirmation of negative stereotypical beliefs about mental illness in the community can lead to behavioral change, and reduced anxiety and enhanced empathy for mental health difficulties sufferers [26]. The intergroup theory used for stigma interventions in different countries is applied in developed or lower-middle-income countries. In these interventions, mental health - based prejudice levels in the study groups were similar and social contact effectively decreased social distance from people with mental illness $[25,27]$.

\section{Conclusion}

There are some studies showing how social distance changing affected mental illness situations in Turkey. These early Turkish researches showed the type of pathology related to social distance [28]. This evidence shows that economically and culturally different populations have similar stigmatization and discrimination problems related to mental illnesses. There are effective anti-stigmatization strategies but low and middle-income countries have less intervention programs than developed countries. Short-term benefits of population-based interventions have not produced consistent successful results and knowledge increasing techniques in the population. If the population is big, interventions increase, and are less effective. There are different types of interventions and different types of specific groups in the field, whereas the intervention strategies should be more focused on group qualities and needs. There is no single solution for fighting against stigma. There is a need for long term intervention strategies and continuous outcome follow-ups, and also for booster doses where intervention can be more effective.

Distal outcomes such as suicide, absence of full social participation, and denial of human rights, specifically preventing research must be addressed to discover which interventions can be effective. Interventions targeted at groups such as employers, the public, and professionals together for decreasing stigmatization can increase prevention of these outcomes, but there is an information gap in understanding correct specific intervention selection, and specific impact on results.

In Turkey, stigmatization of mental illnesses delayed or disallowed help-seeking and access to health care. This plays a potential role in self-harm and suicide, the denial of human rights, and barriers to full social participation in all parts of daily life such as employment and family life. Recent reviews have inspected the influence of stigma on access to mental health care and determined that stigma had a significant negative effect $[29,30]$. Research has also identified several demographic factors associated with suicidal ideation and eventual suicide including social isolation, psychiatric hospitalization, social and economic disadvantage, psychological vulnerability, and hopelessness, which could be associated with stigma [31]. Prevention of stigmatization and discrimination should be an important program target for a mental health action plan of the
Turkish Ministry of Health. According to this plan, intervention strategies should implicate local communities in all the country.

Financial Support: The author has no relevant financial information to disclose.

Conflict of Interest: The author has no potential conflicts to declare.

\section{REFERENCES}

[1] Thornicroft G. Shunned: Discrimination against people with mental illness. Oxford: Oxford University Press, 2006.

[2] Evans-Lacko S, Courtin E, Fiorillo A, et al. The state of the art in European research on reducing social exclusion and stigma related to mental health: a systematic mapping of the literature. Eur Psychiatry 2014; 29: 381-9. doi: 10.1016/j. eurpsy.2014.02.007

[3] Yang L, Cho SH, Kleinman A. Stigma of mental illness. In: Patel V, Woodward A, Feigin V, Quah SR, Heggenhougen K, eds. Mental and Neurological Public Health: A Global Perspective. Boston: Elsevier, 2010.

[4] Yamaguchi S, Wu SI, Biswas M, et al. Eff ects of short-term interventions to reduce mental health-related stigma in university or college students: a systematic review. J Nerv Ment Dis 2013; 201: 490-503. doi:10.1097/NMD.0b013e31829480df

[5] Mansouri N, Gharaee B, Shariat SV, et al. The change in attitude and knowledge of health care personnel and general population following trainings provided during integration of mental health in Primary Health Care in Iran: a systematic review. Int J Ment Health Syst 2009; 3:15. doi: 10.1186/17524458-3-15.

[6] Corrigan PW, Morris SB, Michaels PJ, Rafacz JD, Rüsch $\mathrm{N}$. Challenging the public stigma of mental illness: a metaanalysis of outcome studies. Psychiatr Serv 2012; 63: 963-73. doi: 10.1176/appi.ps.201100529.

[7] Jorm AF, Kitchener BA, O’Kearney R, Dear KB. Mental health fi rst aid training of the public in a rural area: a cluster randomized trial [ISRCTN53887541]. BMC Psychiatry 2004; 4: 33. doi: 10.1186/1471-244X-4-33.

[8] Kitchener BA, Jorm AF. Mental health fi rst aid training in a workplace setting: a randomized controlled trial [ISRCTN13249129]. BMC Psychiatry 2004; 4: 23. doi: 10.1186/1471-244X-4-23.

[9] Gulliver A, Griffi ths KM, Christensen H, et al. Internet-based interventions to promote mental health help-seeking in elite athletes: an exploratory randomized controlled trial. J Med Internet Res 2012; 14: e69. doi: 10.2196/jmir.1864

[10] Jorm AF, Christensen H, Griffi ths KM. The impact of beyondblue: the national depression initiative on the Australian public's recognition of depression and beliefs about treatments. Aust N Z J Psychiatry 2005; 39: 248-54. doi: 10.1080/j.1440-1614.2005.01561.x.

[11] Thornicroft C, Wyllie A, Thornicroft G, Mehta N. Impact of the "Like Minds, Like Mine" anti-stigma and discrimination campaign in New Zealand on anticipated and experienced 
discrimination. Aust N Z J Psychiatry 2014; 48: 360-70. doi: 10.1177/000.486.7413512687

[12] Rüsch N, Xu Z. Strategies to reduce mental illness stigma. In: Gaebel W, Roessler W, Sartorius N, eds., The Stigma of Mental Illness - End of the Story? Switzerland:Springer International Publishing, 2017:451.

[13] Stuart H. Sartorius N. Opening Doors: The global programme to fight stigma and discrimination because of schizophrenia. In: Gaebel W, Roessler W, Sartorius N, eds. The Stigma of Mental Illness - End of the Story? Switzerland: Springer International Publishing, 2017.

[14] Robertson J. See me Scotland case study. In: Gaebel W, Roessler W, Sartorius N, eds. The Stigma of Mental Illness - End of the Story? Switzerland: Springer International Publishing, 2017.

[15] Cunningham R. Peterson D, Collings S. Like Minds, Like Mine: Seventeen years of countering stigma and discrimination against people with experience of mental distress in New Zealand. The Stigma of Mental Illness - End of the Story? Switzerland: Springer International Publishing, 2017:263.

[16] Harman G, Heath J, Australian country perspective: the work of beyond blue and SANE Australia. In: Gaebel W, Roessler W, Sartorius N, eds. The Stigma of Mental Illness - End of the Story? Switzerland:Springer International Publishing. 2017.

[17] Stuart H. Reducing the stigma of mental health, global mental health. 2016; 3, e17, 1-14. doi: 10.1017/gmh.2016.11

[18] Corrigan PW, Morris SB, Michaels PJ, Rafacz JD, Rüsch $\mathrm{N}$. Challenging the public stigma of mental illness: a metaanalysis of outcome studies. Psychiatr Serv 2012; 63, 963-73. doi:10.1176/appi.ps.201100529

[19] Moll S, Patten S, Stuart H, Kirsh B, MacDermid J. Beyond Silence: protocol for a randomized parallel-group trial comparing two approaches to workplace mental health education for healthcare employees. BMC Med Educ 2015;15: 78. doi:10.1186/s12909.015.0363-9

[20] Hocking B. Stigma watch: Tackling stigma against mental illness and suicide in the media: A SANE report. Australia: SANE, 2013.
[21] Corker E, Hamilton S, Henderson C, et al. Experiences of discrimination among people using mental health services in England 2008-11. Br J Psychiatr 2013; 202: S58-63. doi:10.1192/bjp.bp.112.112912

[22] Brohan E, Clement S, Rose D, Sartorius N, Slade M, Thornicroft G. Development and psychometric evaluation of the Discrimination and Stigma Scale (DISC). Psychiatry Res 2013; 208: 33-40. doi:10.1016/j.psychres.2013.03.007

[23] World Health Organization. Stop exclusion. Dare to care. Geneva:World Health Organization, 2001.

[24] Pettigrew TF, Tropp LR, Wagner U, Christ O. Recent advances in intergroup contact theory. Int J Intercult Relat 2011; 35: 271-80. doi:10.1016/j.ijintrel.2011.03.001

[25] Pettigrew TF, Tropp LR. A meta-analytic test of intergroup contact theory. J Pers Soc Psychol 2006; 90: 751-83. doi:10.1037/0022-3514.90.5.751.

[26] Kolodziej ME, Johnson BT. Interpersonal contact and acceptance of persons with psychiatric disorders: a research synthesis. J Consult Clin Psychol 1996; 64: 1387-96. doi: 10.1037//0022-006x.64.6.1387

[27] Arkar H, Eker D. Infl uence of having a hospitalized mentally ill member in the family on attitudes toward mental patients in Turkey. Soc Psychiatry Psychiatr Epidemiol 1992; 27: 151-5. doi:10.1007/BF00788762.

[28] Schomerus G, Angermeyer MC. Stigma and its impact on helpseeking for mental disorders: what do we know? Epidemiol Psychiatr Soc 2008; 17: 31-7. doi:10.1017/s1121189x00002669

[29] Thornicroft G. Stigma and discrimination limit access to mental health care. Epidemiol Psychiatr Soc 2008; 17: 14-9. doi:10.1017/s1121189x00002621

[30] Hawton K, Casañas I Comabella C, Haw C, Saunders K. Risk factors for suicide in individuals with depression: a systematic review. J Aff Ect Disord 2013; 147: 17-28. doi:10.1016/j. jad.2013.01.004.

[31] Republic of Turkey National Mental Health Policy. The Ministry of Health of Türkiye General Directorate of Primary Health Care. Ankara: Ministry of Health, 2006. 